\title{
Teoría del Nuevo Cine Latinoamericano: de la militancia al neobarroco
}

Paul A. Schroeder Rodríguez Northeastern Illinois University

Resumen

Este ensayo examina la transición de la militancia al neobarroco en la teoría del Nuevo Cine Latinoamericano, a través de un análisis de manifiestos y películas de Fernando Birri, Glauber Rocha, Jorge Sanjinés y Paul Leduc. El estudio concluye que el cambio hacia una praxis neobarroca significó un giro hacia un proyecto de izquierda más inclusivo y revolucionario ligado a lo que Aníbal Quijano llama el privado-social.

Palabras clave: Nuevo Cine Latinoamericano, manifiestos, neobarroco, privado-social, Fernando Birri, Glauber Rocha, Jorge Sanjinés, Paul Leduc.

\section{Abstract}

This article examines the transition from militancy to neobaroque in the theory of New Latin American Cinema, by analysing manifestos and films by Fernando Birri, Glauber Rocha, Jorge Sanjinés, and Paul Leduc. The study concludes that the shift to a neobaroque praxis signified a turn towards a more inclusive and revolutionary leftist project linked to what Anibal Quijano calls the private-social. 
Keywords: New Latin American Cinema, manifestos, neobaroque, private-social, Fernando Birri, Glauber Rocha, Jorge Sanjinés, Paul Leduc.

Dor varios años he estado estudiando cuál ha sido el aporte del 1 cine latinoamericano al desarrollo de una praxis neobarroca. Ya en un artículo reciente analicé un arco que va desde las primeras películas del Nuevo Cine Latinoamericano (NCLA), que son claramente militantes, hasta las películas de los años ochenta, que son claramente neobarrocas:

El Nuevo Cine Latinoamericano se desarrolló en dos fases sucesivas aunque no excluyentes la una de la otra. La primera fue una fase militante cuya estética documentalista predomina en los años 60, cuando muchos cineastas vieron su trabajo como parte integral de un proyecto de liberación política, social y cultural. La segunda fase, neobarroca, predomina en los años 70 y 80 . Durante esta segunda fase muchos de los mismos cineastas que habían sido militantes en los años 60 reconceptualizan su trabajo para responder a un proyecto más complicado: desarrollar el equivalente cinematográfico de un discurso político pluralista identificado con una emergente sociedad civil y opuesto al autoritarismo y monologismo de los regímenes represivos que se impusieron en la región a partir de los finales de los 60 (Schroeder, 2011: 16).

Ahora quisiera abordar cómo se teorizó esa transición de la militancia al neobarroco, algo que tuve la oportunidad de explorar en el contexto de un seminario sobre cine y neobarroco que ofrecí en la Universidad de Guanajuato la semana del 11 de marzo de 2013. ¿Qué es el neobarroco latinoamericano? Para Gonzalo Celorio, es un fenómeno muy extendido entre narradores latinoamericanos del siglo XX, que consiste en utilizar tropos del barroco, sobre todo la parodia, para ponderar, seleccionar, asumir, fijar, recuperar y preservar los valores culturales heredados del barroco desde una 
actitud crítica (Celorio, 2000: 23). Para Irlemar Chiampi también se trata de la recuperación de formas y estrategias del barroco en pleno siglo XX, pero su análisis en Barroco y modernidad va más lejos porque incorpora una dimensión diacrónica ausente en Celorio. Concretamente, Chiampi argumenta que los ciclos y reciclajes del barroco en América Latina "coinciden... con los ciclos de ruptura y renovación poética que compendian su proceso: 1890, 1920, 1950, 1970” (2001: 18). Los ejemplos que Chiampi analiza son todos del mundo de la literatura. En el primer ciclo, Rubén Darío rinde homenaje a los grandes poetas del barroco español en el prólogo de Prosas profanas (1896): Góngora, Quevedo y Garcilaso, y los coloca a la par de Verlaine. En el segundo, el Borges ultraísta de 1921 "celebra la tendencia «jubilosamente barroca» de un Ramón Gómez de la Serna, a la par del creacionismo de Huidobro, [y] evoca constantemente a Quevedo, Gracián, y sobre todo a Góngora” (19). En los años cincuenta, Lezama Lima celebra "la dificultad del sentido" barroco con una poesía que rompe "los nexos (lógicos, reconocibles) causales entre el significante y sus referencias ya culturalizadas" (20). Y en el más reciente ciclo, la plena realización del barroco en el siglo XX se manifiesta en obras abiertamente neobarrocas, entre ellas Cobra (Severo Sarduy, 1972), donde la "sobrecodificación lingüística y pictórica recobran la concepción barroca del texto como escenario de un desorden compuesto y artificioso"; La importancia de llamarse Daniel Santos (Luis Rafael Sánchez, 1989), novela que "capta el sesgo popular y kitsch del barroco nuestro, liberándose del intelectualismo de las citas eruditas para deleitarnos con las letras catárticas de las canciones que sobreviven en la memoria de todo latinoamericano"; Yo El Supremo (Augusto Roa Bastos, 1974), donde "múltiples juegos de palabras [...] diseñan las quimeras de la similitud entre las palabras y las cosas"; ;Oh Hada Cibernética! (Carlos Germán Belli, 1962), cuyo rescate de formas poéticas y lingüísticas del barroco "festeja 
la modernización del barroco "clásico» con humor e ironía”; y $G a$ láxias (Haroldo de Campos, 1964-1976), donde el poeta "pone en escena, en la materialidad fónica y semántica de cada palabra, las múltiples potencialidades de la agudeza gracianesca combinada con la joyceana" (22-29).

Barroco y modernidad comienza con una afirmación: "Todo debate sobre la modernidad y su crisis en América Latina que no incluya el barroco resulta parcial e incompleto" (Chiampi, 2001: 9). Esta sentencia cobra especial relevancia para el estudio del cine - arte eminentemente moderno cuya historia siempre ha reflejado las tensiones y fisuras que existen entre los diferentes proyectos de la modernidad tardía-, y así como Chiampi pudo identificar cuatro ciclos y reciclajes del barroco en la literatura latinoamericana, yo he podido identificar dos en el cine latinoamericano. El primero se dio durante la primera vanguardia del cine latinoamericano, y sus películas ejemplares son Limite (Mario Peixoto, Brasil, 1929) y iQue viva México! (Sergei Eisenstein, México, 1931) (Schroeder Rodríguez, en prensa). El segundo ciclo, como veremos en este ensayo, ocurre durante la fase neobarroca del Nuevo Cine Latinoamericano.

\section{Discursos múltiples de la modernidad}

Antes de proceder al análisis de la transición entre militancia y neobarroco en la teorización del Nuevo Cine Latinoamericano, haré un breve aparte sobre los tres discursos de la modernidad que han prevalecido en América Latina en el último siglo. Son las llamadas tres vías: el liberalismo, el socialismo de Estado y el corporativismo de Estado. Los discursos de estos tres proyectos tienen sus variantes, y en la práctica han estado muy mezclados. Sin embargo, podemos resumir diciendo que la premisa del discurso liberal de la modernidad es que un mercado libre basado en ciudadanos 
privados y capital privado es el sistema que más eficientemente genera riquezas y distribuye productos; que el socialismo de Estado parte de la premisa que una clase obrera que ha tomado el control del Estado es quien mejor puede maximizar el empleo y distribuir las riquezas generadas, a través de una planificación centralizada de la economía; y que el corporativismo de Estado, o tercera vía, define la sociedad como un organismo político cuyas partes constituyentes son actores sociales con diferentes grados de privilegio o importancia - ejército, banca, Iglesia, intelectuales y sindicatos, entre otros - que el Estado corporativista dirige y coordina para el 'bien común'. Sean de izquierda o de derecha, el liberalismo, el socialismo de Estado y el corporativismo de Estado se basan todos en una racionalidad instrumental que justifica la explotación de recursos humanos y naturales en función de la máxima eficiencia en el uso del capital, sea éste privado o del Estado. Por último, en cuanto a la construcción de narrativas, todos asumen y reproducen el tiempo lineal y el espacio continuo propios de la razón instrumental.

Por otra parte, existe un cuarto discurso de la modernidad que recupera, no el barroco corporativista de la Contrareforma, sino el potencial subversivo del Barroco de Indias que artistas como Kondori y Aleijadinho lograron plasmar en la segunda mitad del siglo XVIII. Es este uso contestatario del barroco, censurado y soterrado desde finales del siglo XVIII hasta muy entrado el siglo XIX, lo que tantos artistas latinoamericanos han venido recuperado desde principios del siglo XX para cuestionar las bases mismas de la racionalidad instrumentalizadora, como lo son el tiempo lineal, el espacio continuo, la relación causa-efecto, y los binarismos tradicionales. En concreto, yo argumentaría que en lugar de expresar una perspectiva propia de la razón instrumental, los artistas latinoamericanos del neobarroco expresan una perspectiva liminar análoga a lo que Aníbal Quijano llama el privado-social, 
esa combinación de un privado que no es individual y un público que está fuera del Estado, y que por ello "repone la reciprocidad como el fundamento de la solidaridad y de la democracia" (Quijano, 1988: 26). Este privado-social —ni público ni privado, ni individualista ni colectivista, sino intermedio, como los ayllus o las cofradías coloniales para las cuales Kondori y Aleijadinho realizaron trabajos - genera una racionalidad substantiva que valora la reciprocidad, la solidaridad y la democracia por sobre fines como la eficiencia económica del liberalismo y del socialismo, o la jerarquización, propia del corporativismo, de seres humanos según su pertenencia en una u otra de las asociaciones reconocidas por el Estado.

El ejemplo que usa Quijano como evidencia de un discurso privado-social llevado a la práctica en el siglo XX son las organizaciones vecinales de las barriadas pobres en el Perú. Quijano reconoce la posición marginal de estas organizaciones dentro de un contexto dominante capitalista, pero las celebra como alternativa al capitalismo privado y al capitalismo de Estado:

Instaladas esas instituciones del privado-social [...] dentro del contexto dominante del privado-particular y de su Estado, no pueden dejar de ser afectadas por el impacto de éstos, o por la lógica dominante del capital. [...] A pesar de ello, la reciprocidad, la solidaridad, la democracia, resisten [...] y las instituciones del nuevo privado-social y de sus instituciones públicas-no-estatales, [...] se reproducen, aumentan de número y de tipo, y se van convirtiendo en una nueva y vasta red de organización de una nueva “sociedad civil" (1988: 28).

Quijano escribió estas líneas en los años ochenta, cuando para muchos se hizo evidente que las utopías ofrecidas por el liberalismo, el socialismo de Estado, y el corporativismo de Estado no se materializarían, puesto que siempre terminaban sometidas a los intereses 
de las élites de turno. En el privado-social, por otra parte, se evitan las falsas utopías porque en él no hay élites que decidan y sub-élites que obedezcan, sino que democráticamente se decide cómo se generarán y cómo se distribuirán las riquezas.

\section{El privado-social y el neobarroco}

Así como el discurso de la modernidad liberal plantea una utopía futura basada en el privado-particular; el discurso de la modernidad socialista plantea una utopía futura basada en el privadoestatal; y el discurso de la modernidad corporativista plantea una utopía futura basada en la coordinación del privado-particular y del privado-estatal; el discurso de la modernidad del privado-social propone una utopía realizable en el presente: dinámica, multitemporal y pluriforme; basada en los valores de reciprocidad, solidaridad y democracia; y sin sacrificios de individuos o grupos en función de una futura ilusión.

En el cine, las diferencias entre estos cuatro discursos de la modernidad se plasman principalmente a nivel narrativo: el liberalismo privilegia al individuo privado (típicamente encarnado en personajes blancos, heterosexuales y propietarios); el socialismo privilegia a la clase obrera (típicamente encarnada en personajes obreros, blancos y heterosexuales); el corporativismo privilegia la armonización entre el capital y la mano de obra (típicamente encarnados en personajes blancos y heterosexuales); y el privadosocial privilegia la encarnación de personajes que no son hombres blancos heterosexuales, y que llamaré individuo-colectivo, término paradójico que, sin embargo, capta la idea de que se trata de un personaje que encarna el también paradójico privado-social postulado por Quijano.

A partir de estas diferencias, podemos vincular ciertos periodos del cine latinoamericano con discursos específicos de la moderni- 
dad. Por ejemplo, el cine mudo latinoamericano presenta casi exclusivamente un discurso liberal de la modernidad. Luego, durante el cine clásico, cristaliza un discurso corporativista. Por su parte, durante la fase militante del NCLA, en los años sesenta, irrumpió un discurso socialista inspirado en la Revolución Cubana. Y más recientemente, durante la fase neobarroca de este Nuevo Cine, en los años setenta y ochenta, los cineastas más originales utilizaron una praxis neobarroca - que por su misma estructura descentralizadora se prestaba para lanzar una crítica radical a las estructuras verticales de poder y a la idea de que la siempre futura utopía requiere sacrificios en el presente- para plasmar un discurso de la modernidad del privado-social.

\section{De la militancia al neobarroco}

Militancia es sin duda lo primero que viene a la mente de muchos al escuchar la frase "Nuevo Cine Latinoamericano". De hecho, en las tres antologías del NCLA que han sido publicadas - Twenty Five Years of New Latin American Cinema, editada por Michael Chanan en 1983; Hojas de Cine, cuyos tres volúmenes fueron publicados en México en 1988; y New Latin American Cinema, editada por Michael Martin en 1997- sólo se antologizan manifiestos militantes, entre ellos:

- "Cine y subdesarrollo" (1962), de Fernando Birri

- "Estética del hambre" (1965), de Glauber Rocha

- "Hacia un tercer cine" (1968), de Fernando Solanas y Octavio Getino

- "Por un cine imperfecto" (1969), de Julio García Espinosa, y

- "Problemas de la forma y del contenido en el cine revolucionario" (1978), de Jorge Sanjinés. 
Estos cinco manifiestos son ya canónicos, y merecen estar en toda antología del Nuevo Cine Latinoamericano. Sin embargo, merecerían también estar manifiestos neobarrocos que hasta ahora no han formado parte del canon, entre ellos:

- "Por un cine cósmico, delirante y lúmpen" (1978), de Fernando Birri

- "Estetyka do Sonho" (1971), de Glauber Rocha

- "El plano secuencia integral” (1989), de Jorge Sanjinés, y

- Poética del cine (1995), de Raúl Ruiz.

Estos manifiestos neobarrocos son tan importantes como los manifiestos militantes, y si los ignoramos, ignoramos también una comprensión más completa y compleja de lo que fue el Nuevo Cine Latinoamericano como proyecto que transita de la militancia al neobarroco tanto en la práctica como en la teoría. Lo que sigue es por lo tanto un primer acercamiento crítico a esa comprensión más compleja y completa de la teoría del NCLA a través de la obra de cuatro directores representativos del NCLA: Fernando Birri, Glauber Rocha, Paul Leduc y especialmente Jorge Sanjinés.

\section{Fernando Birri}

En "Cine y subdesarrollo" (1962), Birri escribe: "Nos interesa hacer un hombre nuevo, una sociedad nueva, una historia nueva, y por lo tanto un arte nuevo, un cine nuevo. Urgentemente. [...] $[\mathrm{P}]$ onerse frente a la realidad con una cámara y documentarla, filmar realistamente, filmar críticamente, filmar con óptica popular el subdesarrollo" (Birri, 1988: 17 y 22). Aquí hallamos resumida la lista de los tropos centrales de la fase militante: hombre nuevo, cine nuevo, urgentemente, realismo, popular, críticamente, subdesarrollo. El extracto es también una buena descripción del film 
más conocido de su autor, Tire dié (1956-1958), un cortometraje ampliamente considerado como parte aguas entre el neorrealismo de los años cincuenta y el NCLA de los sesenta. Quince años más tarde la praxis de Birri se habrá transformado radicalmente. En 1978, y tras un esfuerzo descomunal que duró una década, termina y proyecta en Italia Org. Hermann Herlinghaus, en un minucioso estudio de la película, observa:

Mientras un largometraje de ficción promedio posee entre 600 y 800 secuencias montadas, el número de empalmes en el negativo de $O R G$ se suma a 26,625 , logrado en 8,340 horas de trabajo de tres mujeres. En la banda sonora (un año de composición), con 616 bandas de premezcla y 429 de mezcla, se han sintetizado una duración original de 102 horas de conversación, ruidos, música, incluyendo 500 efectos de repertorio. La clasificación del color, desde el punto de vista cuantitativo, con sus 6,524 cambios de luces, es un trabajo equivalente al de 10 películas (promedio habitual 700 cambios de luces por película). Se registran 257,368 fotogramas y una cantidad de material virgen usado de 419,922 metros de cinta cinematográfica de 33 tipos diferentes,datos que son atípicos, digamos excesivos, dentro de cualquier catálogo de producción. [...]

Se visualiza como en el caleidoscopio una multitud de más de 300 protagonistas hipotéticos. Entre ellos, se encuentran Salvador Allende, Johann Sebastian Bach, Roland Barthes, [...] Ernesto "Che" Guevara [...], y, además, mendigos, [...] alquimistas, [...] y ofendidos.

El procedimiento estético que permite presentar tal pluralidad es el principio del montaje-collage que, en sus raíces, se remonta al fotomontaje dadaista [...] Parafraseando a Benjamin, el que viene a hacerse mago, es el camarógrafomontajista. El espectador se siente involucrado en un conjunto abierto de signos que Fernando Birri [...] lleva al extremo 
de un método videoclip, indigerible por su barroquísimo caos audiovisual (Herlinghaus, 2011: 121-122).

Este exceso de significantes, indigerible por su "barroquísimo caos audiovisual" sitúa la película con firmeza dentro de la fase neobarroca del Nuevo Cine Latinoamericano, como también lo hace el manifiesto que Birri escribió en 1978 para acompañar la película. El manifiesto está intitulado, barrocamente, "Manifiesto $O R G$ (Manifiesto del cosmunismo o comunismo cósmico). Por un cine cósmico, delirante y lumpen”, y polemiza:

$[\mathrm{N}]$ o habrá revolución duradera sin revolución del lenguaje comunismo sensual hedonista erótico vísceras pensantes: cosmunismo fabricación de un poema o de una novella choque artesanía vs. industria comunismo cósmico y mágico por un cine cósmico delirante y lumpen (entre cine y no-cine o más-allá-del-cine: filmunculus) [...] (técnicas de montaje pitagóricas, oraculares y alquímicas) [...] por un cine cósmico delirante y lúmpen comunismo sensual hedonista erótica vísceras pensantes: cosmunism (un film test de Rorschach) por lo tanto ideologizar todo pero además sensorializar todo tabula rasa: cine desde cero para experimentear $O R G$ ("sólo para locos") fabricación de un poema o de un... (Birri, 1996: 19-20).

El manifiesto, por decirlo así, justifica la plétora de imágenes contrastantes en la película con un lenguaje también pletórico en contrastes que no se cancelan ("entre cine y no-cine, vísceras pensantes"). Más al grano, Birri teoriza la película como una "tabula rasa: cine desde cero", un tropo análogo al "espacio fundador" que Severo Sarduy teoriza en su libro Barroco:

En el espacio simbólico del barroco [...] encontraríamos la cita textual o la metáfora del espacio fundador, postulado por la Astronomía contemporánea; en la producción actual, la expansión 
o la estabilidad del universo que supone la Cosmología de hoy, indistinguible de la Astronomía: no podemos ya observar sin que los datos obtenidos nos remitan, por su magnitud, al "origen" del universo (Sarduy, 1974: 14).

Org es como ese espacio simbólico del barroco donde el exceso de imágenes contrastantes nos remite no a una utopía futura sino a la realización de la utopía en el presente. Se trata de un espaciotiempo simbólico que incluye todas nuestras posibilidades de creación sin que unas tengan que forzosamente preceder a otras. No en balde Sarduy titula el primer capítulo de Barroco "0: Cámara de Eco", con el número cero en lugar del número uno. Y no en balde la imagen central de este "primer" capítulo es la de una cámara donde "a veces el eco precede la voz" (13). Esta idea de un efecto que puede preceder a la causa, aplicada a $\mathrm{Org}$, sugiere que el proyecto de Birri es nada más y nada menos que la creación de una utopía en el presente, donde el amor, encarnado por la muy liberada Shuick (Lidija Juracik), y la solidaridad, encarnada en la hermandad entre los protagonistas Zohomm (Terence Hill) y Grr (Isaac Tweg Obn), son punto de partida y no de llegada de un proyecto radicalmente revolucionario basado en la práctica cotidiana del amor y la solidaridad.

\section{Glauber Rocha}

El tránsito de una teorización militante a una teorización neobarroca lo hace también Glauber Rocha. En "Eztetyka da Fome”, un manifiesto abiertamente militante escrito en 1965, y que se conoce también con los nombres "Estética del hambre" y "Estética de la violencia”, Rocha escribe:

El Cinema Novo demuestra que el comportamiento exacto de un hambriento es la violencia; y una estética de la violencia, antes 
de ser primitiva, es revolucionaria. [...] Mientras no se levante en armas el colonizado es un esclavo: fue preciso un primer policía muerto para que el francés percibiera un argelino. [E]sa violencia, con todo, no está incorporada al odio, como tampoco diríamos que está relacionada al viejo humanismo colonizador. El amor que esta violencia encierra es tan brutal cuanto la propia violencia, porque no es un amor de complacencia sino un amor de acción y transformación (Rocha, 1997: 60; traducción mía).

La secuencia en Dios y el diablo en la tierra del sol (1963) donde Manoel (Geraldo del Rey) mata al terrateniente es quizás el mejor ejemplo de esta estética de la violencia llevada a la pantalla grande. Ocho años después de esta película, Rocha escribe su "Eztetyka do Sonho" ('Estética del sueño', 1971), donde señala:

Una obra de arte revolucionario debería no sólo actuar de modo inmediatamente político, sino también promover la especulación filosófica, creando una estética del eterno movimiento humano rumbo a su integración cósmica. La existencia discontinua de este arte revolucionario en el Tercer Mundo se debe fundamentalmente a las represiones que hace el racionalismo [instrumental] (Rocha, 2004: 47; traducción mía).

Rocha pone en práctica este llamado en Der Leone Have Sept Cabeças (1971), pero es en La edad de la tierra (1980) donde culmina el desarrollo de un lenguaje neobarroco lleno de símbolos y teatralidad para criticar el racionalismo instrumental y señalar el camino hacia lo que él llama la integración cósmica de la humanidad. La edad de la tierra es difícil de resumir narrativamente. Conceptualmente, sin embargo, la sinopsis del director capta la ambición épica y la complejidad alegórica de su película más experimental:

La película muestra un Cristo-Pescador, el Cristo interpretado por Jece Valadão; un Cristo-Negro, interpretado por Antonio Pi- 
tanga; muestra el Cristo que es el conquistador portugués, Don Sebastián, interpretado por Tarcísio Meira; y muestra el Cristo guerrero-Ogúm de Lampião, intepretado por Geraldo Del Rey. Es decir, los cuatro Caballeros del Apocalipsis que resucitan a Cristo en el Tercer Mundo, recontando el mito a través de cuatro evangelistas: Mateo, Marcos, Lucas y Juan, cuya identidad es revelada en el film casi como si fuese un Tercer Testamento. Y el film asume un tono profético, realmente bíblico y religioso. (Rocha, 1980: internet)

En una secuencia clave, el Cristo Negro (Antonio Pitanga) está comenzando a dar un discurso sobre los derechos del hombre en las afueras de la recién fundada Brasilia, cuando la voz en off de Glauber Rocha, en tono entre de sermón y meditativo, desplaza el sonido diegético con este discurso:

Toda esta ideología de amor se concentraría en el cristianismo, que es una religión venida de los pueblos africanos, asiáticos, europeos, latinoamericanos, de los pueblos totales. Un cristianismo que no se realiza solamente en la Iglesia Católica sino también en todas las religiones que encuentran en sus símbolos más profundos, más recónditos, más eternos, más subterráneos, más perdidos, la figura de Cristo. Un Cristo que no está muerto sino que está vivo, desparramando amor y creatividad. La búsqueda de la eternidad y la victoria sobre la muerte.

Podríamos decir que el Cristo crucificado, el Cristo muerto, es a la racionalidad instrumental lo que el Cristo vivo, el Cristo revolucionario, es a la racionalidad substantiva, a la integración democrática de la humanidad. Y que por lo tanto, en La edad de la tierra, la nación brasileña, con sus Cristos vivos y muertos, funciona como alegoría del planeta: fractal y pliegue a la misma vez, microcosmos y totalidad de una sociedad en plena transición hacia la integración cósmica y material de los marginalizados. 


\section{Jorge Sanjinés}

En el caso de Jorge Sanjinés la transición de la militancia al neobarroco es menos abrupta y más prolongada. En una ponencia del año 1977 Sanjinés todavía equipara militancia y revolución:

El cine militante de la actualidad encuentra su más claro origen en [...] los primeros documentales de importancia que se hacen en Bolivia, a través del organismo oficial creado por el gobierno revolucionario en 1952. [...] [A partir de esa producción] se desarrolla un cine revolucionario que orienta sus obras dentro de la lucha antiimperialista (Sanjinés, 1988a: 105-106).

Esta función militante, documentalista y revolucionaria del cine se ve claramente en películas como Yawar Mallku (1969), y sobre todo en El coraje del pueblo (1971), donde la narrativa pasa de ser una ficcionalización de un hecho histórico a ser una recreación de un evento histórico concreto. Es decir, pasa de ser de algo tan concreto como lo fue la esterilización de mujeres indígenas en Bolivia por parte de los Cuerpos de Paz de Estados Unidos en Yawar Mallku, a través de una forma del cine comercial como lo es el tener una narrativa impulsada por personajes individualizados con motivaciones de índole psicológico; a ser la recreación de un evento histórico concreto (la Masacre de San Juan en las minas Siglo XX y Catavi en Potosí, en 1967), a través de un personaje colectivo (los obreros sindicalizados y sus familias) cuyas motivaciones son de índole social.

Su próxima película, El enemigo principal (1974), comienza a alejarse de la militancia documentalista que caracteriza a El coraje del pueblo, pues ya no se enfoca en un hecho histórico específico sino en el choque cultural entre un grupo de revolucionarios occidentalizados y la comunidad indígena a donde llegan a poner en práctica la teoría del foquismo guerrillero. De hecho, a pesar 
de sus claras referencias al Che Guevara, muerto seis años antes, El enemigo principal no se refiere a su caso específico, sino que es una reflexión mucho más generalizada del rol que tiene la violencia en los procesos de opresión y liberación a nivel local (bajo el gamonalismo) y a nivel global (bajo el imperialismo), dentro de un contexto cultural de fuertes choques entre valores occidentales y valores indígenas. En su ensayo más conocido, "Problemas de la forma y del contenido en el cine revolucionario", publicado en 1978, Sanjinés explica el cambio formal que ya se estaba gestando en esta película:

La comunicación en el arte revolucionario debe perseguir el desarrollo de la reflexión [...] Un filme sobre el pueblo hecho por un autor no es lo mismo que un filme hecho por el pueblo por intermedio de un autor; como intérprete y traductor de ese pueblo se convierte en vehículo del pueblo. Al cambiarse las relaciones de creación se dará un cambio de contenido y paralelamente un cambio formal (Sanjinés, 1988b: 119-120).

El cambio en Sanjinés de ser un cineasta-autor cuya perspectiva es todavía occidental, a ser un intérprete-coautor junto a una colectividad indígena cuya perspectiva es netamente indígena se hará realidad en su próxima y mejor película, La nación clandestina (1989).

\section{La nación clandestina}

La película narra la historia de Sebastián Mamani (Reinaldo Yujira), un indígena aymara cuya vida él va recordando, después de muerto, a través de flashbacks y flashbacks dentro de flashbacks. Lo primero que Sebastián recuerda es la Jacha Tata Danzante, un antiguo baile ritual hasta la muerte que él había presenciado como niño, y cuyo objetivo era paliar las faltas de la comunidad 
para restituir la armonía con la naturaleza y con ella las lluvias que no habían llegado por varios ańos. Luego se suceden nuevos flashbacks, cada uno activado, al modo de Proust en En busca del tiempo perdido, por un azar sensorial. Primero vemos cómo su propia familia lo entrega a una familia criolla de La Paz para servirles de ayuda doméstica, pues la madre cree que así Sebastián tendrá mejores oportunidades en la vida. Ya de adulto, Sebastián vive en una de esas barriadas pobres descritas por Quijano, donde florecen las organizaciones vecindales y con ellas el privado-social. La película, sin embargo, no muestra esta realidad urbana, sino cómo Sebastián va de trabajo en trabajo, sin rumbo y sin conexiones humanas profundas.

Sebastián se gana la vida desde su domicilio, como carpintero de ataúdes, y para ganar más dinero, se enlista en el ejército nacional y luego en el servicio secreto del Estado. Alejado cada vez más de sus raíces, Sebastián se va alcoholizando hasta llegar a cambiarse el apellido de Mamani a Maisman, pensando que eso lo ayudará a escalar socialmente. Por la forma en que la película presenta el cambio de apellido, poco antes de ingresar al servicio secreto y participar en una redada contra unos disidentes, es lícito pensar que la decisión de cambiárselo representa el nadir en la trayectoria de Sebastián, el punto cuando ya ha interiorizado plenamente los valores racistas de la familia criolla que lo había adoptado / comprado, del ejército, y del servicio secreto. Tras la redada Sebastián se siente peor que nunca. Cuando su hermano Vicente lo encuentra embriagado en una cantina, se lo lleva con él a Willkani, el ayllu al que ambos pertenecen. En Willkani Sebastián es recibido como un hijo pródigo, e inclusive es electo como representante de Willkani ante las autoridades del Estado en La Paz, para negociar una ayuda alimenticia. La oferta de ayuda divide al ayllu. Mientras unos están a favor de recibirla, otros advierten que este tipo de ayuda siempre ha traído más dependencia y pobreza. A pesar de estas diferencias 
de opinión, Sebastián va a La Paz como representante de su ayllu, y unilateralmente decide aceptar la ayuda, vender parte de ella y quedarse con el dinero.

Entretanto, Sebastián se "enamora" de Basilia (Delfina Mamani), una joven mujer de su ayllu. Un día la encuentra sola, pero en lugar de tratarla con respeto y carińo, le comienza a tirar piedritas hasta acorralarla en contra de un precipicio, todo filmado en un plano general donde los personajes son como miniaturas dentro de un panorama andino inmenso, ayudando así al espectador a tomar distancia sobre lo representado. No lo vemos en pantalla, pero podemos asumir que la violó porque la última toma de la secuencia la muestra atrapada entre Sebastián y el precipicio. En su violencia y corrupción, este primer Sebastián encarna la actitud machista y racista de la nación oficial hacia la cultura indígena, como si lo natural fuera que la cultura indígena esté ahí para ser violada y vendida.

Cuando los ancianos del ayllu se enteran del acto de corrupción, convocan una reunión y deciden expulsar a Sebastián de la comunidad. Paradójicamente, aquí comienza la transformación de Sebastián en sujeto aymara. De regreso en La Paz, y tras una borrachera descomunal, manda hacerse una máscara ceremonial para bailar la Jacha Tata Danzante, ordena el vestuario correspondiente, y máscara en mano, emprende a pie su viaje hacia Willkani. Durante el viaje hay varios flashbacks adicionales, y una secuencia importante donde un estudiante universitario está siendo perseguido por las fuerzas represivas del Estado. Cuando se hace evidente que unas indígenas no pueden ayudarlo porque no entienden el castellano, el estudiante reacciona violentamente con insultos racistas. Se trata de un comentario crítico al doble discurso de un sector de la intelectualidad criolla de izquierda, que dice luchar por los indígenas, pero que jamás se interesa en conocer su lengua, cultura o historia. 
Tras un tenso encuentro con las mismas fuerzas armadas que perseguían —y, de hecho, matan — al estudiante, Sebastián llega a las afueras de su pueblo natal, donde los niños lo reciben con curiosidad y algarabía por la vestimenta y la máscara que lleva puestas. Pronto llega el shamán del ayllu (Roque Salgado). Sebastián respetuosamente le explica sus intenciones al shamán, y el shamán lo deja proceder tras consultarlo con los ancianos y ancianas del ayllu. Caso seguido, llegan también los sobrevivientes de una masacre de obreros en las minas cercanas al ayllu. La primera toma de los sobrevivientes es un plano general muy similar a una de las tomas iniciales en El coraje del pueblo, en donde unos mineros indígenas marchan hacia unas minas para reclamar sus derechos. En La nación clandestina, sin embargo, la confrontación ya no es entre "obreros" y "patrones", lo cual sería una prolongación de la interpretación marxista que hace El coraje del pueblo de la Masacre de San Juan, sino una confrontación dentro de la misma comunidad indígena. Indignados por la presencia de Sebastián justo cuando ellos traen a varios muertos a cuestas, los mineros comienzan a insultar a Sebastián y a reclamarle al shamán que lo haya dejado pasar. La confrontación entre mineros de un lado, y el shamán que defiende a Sebastián del otro, está filmada toda en un brillantísimo plano secuencia que culmina con el shamán imponiendo su punto de vista sobre los indignados mineros, y abriendo paso al desenlace de la película: la danza ritual hasta la muerte, y el cortejo fúnebre de Sebastián, cargado por los indígenas que antes lo habían expulsado. Una vez pasa el cortejo fúnebre ante la cámara, y como punto final, emerge Sebastián de detrás de la cámara, observando con nosotros su propio funeral / reincorporación al ayllu.

El desenlace de La nación clandestina facilita una lectura de Sebastián como un individuo-colectivo que se redime, no sacrificando su propia individualidad dentro de una colectividad indifirenciada, sino armonizando sus propias aspiraciones individuales con 
las necesidades colectivas, y su memoria personal con la memoria colectiva. De hecho, la vida de Sebastián reproduce a nivel individual la historia colectiva de su pueblo a lo largo de varios siglos, de forma tal que su re-incorporación al ayllu a través de la Jacha Tata Danzante anuncia el fin de la nación clandestina y el comienzo de un renacer indígena. Esta transformación ocurre no dentro de un tiempo lineal, sino dentro de un tiempo cíclico que, a nivel individual, va desde una armonía con la naturaleza cuando Sebastián era niño, a una desarmonía durante su largo destierro en La Paz, y finalmente a una renovada armonización con la naturaleza tras un baile hasta la muerte que no es sino un renacer. A nivel colectivo, la trayectoria de Sebastían refleja la trayectoria colectiva que va de la armonía con la naturaleza antes del contacto con los europeos; a una desarmonía de más de cuatro siglos (primero bajo el régimen colonial y luego bajo el régimen republicano); y finalmente a una nueva armonización con la naturaleza, bajo una nación transformada que ha logrado salir de la clandestinidad. Es una nación que, como Sebastián, ha sabido superar los traumas de la experiencia colonial y republicana, para nuevamente regirse por los valores de reciprocidad, solidaridad y democracia.

En el artículo titulado "El plano secuencia integral”, publicado en 1989, Sanjinés explica por qué el plano secuencia-una secuencia filmada sin cortes, en una sola toma —es la forma más adecuada para representar la reciprocidad, solidaridad y democracia que la película tematiza:

En la cultura andina el predominio de los intereses del grupo, la tradición colectivista, las prácticas solidarias, la visión de conjunto, de integración y participación componen, en sus significantes ideológicos y en su praxis cotidiana, una propia manera de encarar la realidad, de resolver los problemas de la vida y de la sociedad y los problemas de la propia individualidad, supeditada a lo colectivo. [...] Proponer una técnica narrativa adecuada a la cosmovisión 
andina nos pareció fundamental. [...] Poco a poco, se nos hizo claro que la cámara debía movilizarse sin interrupción y motivada por la dinámica interna de la escena. Sólo así se podía lograr su imperceptibilidad y la integración espacial. Al no fragmentar la secuencia en diversos planos se podía transmitir un ordenamiento nuevo, un ordenamiento propio de los pueblos que conciben todo como una continuidad de ellos (Sanjinés, 1989: 69-70).

Esta inclusividad, donde los bandos opuestos que se enfrentan no se cancelan sino que se concilian dentro de una misma secuencia y un mismo encuadre, como en el plano secuencia integral donde se enfrentan Sebastián y los mineros; y donde además lo hacen a través de un ritual que es individual y colectivo al mismo tiempo, con todo y máscara, espejos y danza; se convierte entonces en la manifestación estética de una cosmovisión neobarroca, una cosmovisión inclusiva de la humanidad muy alejada de la cosmovisión excluyente que Sanjinés plasmó en El coraje del pueblo, donde el montaje dialéctico subraya como intrínseca la irreconciabilidad de los elementos encuadrados y narrados.

\section{Frida, naturaleza viva}

La práctica del cine neobarroco encuentra su plenitud en La nación clandestina y en Frida, naturaleza viva (1989), de Paul Leduc. Leduc es un artista de pocas palabras, y a diferencia de Birri, Rocha, y Sanjinés, quienes han dejado por escrito sus teorías sobre cine militante y cine neobarroco, la teorización que hace Leduc del neobarroco está incorporada a la película misma, en una secuencia donde Trotsky camina solo por el bosque, y escuchamos en voz en off una carta de amor que le dirige a Frida. Esta carta de amor no existe en la realidad, sino que Leduc la inventa a partir del manifiesto “¡Por un Arte Revolucionario Independiente!”, publicado originalmente en 1938. El argumento principal del manifiesto, es- 
crito por André Breton y León Trostky aunque firmado por Breton y Diego Rivera, es que el arte no debe seguir fines que no sean los propios del arte. El manifiesto proclama:

A quienes nos exigieran, para hoy o para mañana, consentir en que el arte se someta a una disciplina que consideramos radicalmente incompatible con sus medios, oponemos una rotunda negativa y nuestra voluntad deliberada de atenernos a la fórmula: toda licencia en arte. [...] Si para el desarrollo de las fuerzas productivas materiales la revolución se ve obligada a erigir un sistema socialista de plan centralizado, para la creación intelectual tiene que establecer y asegurar desde el comienzo un régimen anarquista de libertad individual. [...] [L]a tarea suprema del arte en nuestra época es participar consciente y activamente en la preparación de la revolución. Sin embargo, el artista sólo puede servir en la lucha emancipadora si se ha penetrado subjetivamente de su contenido social e individual, si ha llevado a sus nervios el sentido y el drama de aquélla y si trata libremente de dar una encarnación artística a su modo interior (Bretón y Rivera, 1979: 184).

En Frida, naturaleza viva, la carta ficticia que Trostky le escribe a Kahlo en francés, resume estas ideas con un tono apropiadamente epistolar:

Mi querida Frida, quiero compartir contigo algunos pensamientos sobre la conexión entre el arte genuino y la revolución. El arte proletario y el uso pedagógico del arte no son las únicas formas de cultura revolucionaria. Los trabajadores del mundo necesitan de lo que tú puedes ofrecerles: la idea de la complejidad psicológica del hombre, y la expresión de la fuerza que tiene un instante de pasión (traducción mía).

A través de esta carta ficticia, y de su intertextualidad con uno de los manifiestos de arte más importantes del siglo XX, la película 
teoriza como válido el arte heterodoxo que las pinturas íntimas de Frida representaban en un contexto artístico dominado por el muralismo épico. A la misma vez, la carta valida la experimentación formal y de contenido que Leduc usa para construir su biografía de Kahlo, por tres razones. Primero, porque la película construye un espacio discontinuo y un tiempo fragmentado que cuestionan la continuidad temporal y espacial que requieren los discursos monológicos como el liberalismo, el socialismo de Estado y el corporativismo de Estado. Segundo, porque la película explora un personaje cuyas contradicciones, lejos de desprestigiarla, confirman su humanidad. En concreto, la Frida de Leduc es una mujer liberada que sin embargo se siente incompleta porque no puede tener hijos, y es también una mujer que practica el amor libre y sin embargo no le perdona a Diego que haga lo mismo. Finalmente, la Frida que Leduc construye nos revela, en sus momentos más íntimos - ya sea con el carpintero, con una trabajadora doméstica, con Rivera o con Trostky - su compromiso de vivir el presente, no como un eslabón instrumentalizador de una cadena que apunta hacia alguna futura utopía, sino como un instante privilegiado donde las relaciones sociales son desde ya inclusivas y horizontales.

\section{Conclusiones}

Para concluir, quiero retomar unas palabras que Fernando Birri escribió en 1985, en pleno apogeo de la fase neobarroca del NCLA:

[Estamos intentando desarrollar] un cine activo para un espectador activo, un cine para la liberación [...] económica, política e ideológica, pero también para la liberación de la imagen, y por lo tanto de la imaginación. [...] Este es el nuevo cine poético-político que se está produciendo en América Latina; y es evidencia de la crisis que hemos visto durante este Quinto Festival de La Habana. Crisis es [continúa Birri] una palabra que no gusta a mucha gente 
porque significa sobre todo cambio. Ciertamente, si el cambio es hacia la vejez, la senilidad o la arteriosclerosis, uno entendería [...] Pero si la crisis es el primer grito de un bebé al nacer, o la ruptura o laceración de un adolescente que comienza a plantear preguntas difíciles que quizás no tienen respuesta, entonces es muy positivo porque es una crisis de crecimiento y una crisis de maduración (Birri, 1997: 97-98; traducción mía).

En los ańos cincuenta, los discursos liberal y corporativista que habían imperado durante la primera mitad del siglo XX entraron en plena crisis. Muchos interpretaron esa crisis como un gemido de muerte, sobre todo después del triunfo de la Revolución Cubana, cuando el socialismo irrumpió como alternativa viable. Sin embargo, en los años setenta, el socialismo también entró en crisis, no sólo por invasiones y bloqueos, sino también porque la izquierda ortodoxa se mostraba tan intransigente y populista como la derecha reaccionaria. Por lo tanto, cuando a partir de los ańos setenta artistas como Rocha, Birri, Sanjinés y Leduc le señalan a la izquierda ortodoxa sus contradicciones, prejuicios, y limitaciones, lo hacen como parte de un proyecto de modernidad alternativa, un proyecto que encontró en el neobarroco una praxis adecuada a los nuevos ideales de solidaridad, reciprocidad y democracia.

\section{Bibliografía}

Birri, Fernando, 1988, "Cine y subdesarrollo", en Hojas de cine: Testimonios y documentos del Nuevo Cine Latinoamericano, vol. 1: Centro y Sudamérica, México, Secretaría de Educación Pública / Fundación Mexicana de Cineastas / Universidad Autónoma Metropolitana, pp. 17-22.

, 1996, Por un nuevo nuevo nuevo cine latinoamericano: 1956-1991, Madrid, Cátedra / Filmoteca Española. 
, 1997, "For a Nationalist, Realist, Critical and Popular Cinema”, en Michael Martin (ed.), New Latin American Cinema, vol. 1: Theory, Practices, and Trasnacontinental Articulations, Detroit, Wayne State University Press, pp. 95-98.

Breton, André y Diego Rivera, 1979, “¡Por un arte revolucionario independiente!”, en Raquel Tibol (ed.), Arte y politica, México, Grijalbo, pp. 181-186.

Celorio, Gonzalo, "Del barroco al neobarroco", disponible en: http://www.jcortazar.udg.mx/sites/default/files/celorio.pdf, p. 23, (cosultado el 9/XII/13).

Chanan, Michael (ed.), 1983, Twenty Five Years of New Latin American Cinema, Londres, Channel Four Television.

Chiampi, Irlemar, 2001, Barroco y modernidad, México, Fondo de Cultura Económica.

Quijano, Aníbal, 1988, Modernidad, identidad y utopía en América Latina, Lima, Sociedad y Política Ediciones.

Herlinghaus, Hermann, 2011, "La película ORG (1969/1978) de Fernando Birri", Revista de Critica Literaria Latinoamericana, vol. 37, núm. 73, Lima y Boston, pp. 117-128.

Hojas de Cine, Testimonios y documentos del Nuevo Cine Latinoamericano, 3 vols., 1988, México, Secretaría de Educación Pública / Fundación Mexicana de Cineastas / Universidad Autónoma Metropolitana.

Martin, Michael (ed.), 1997, New Latin American Cinema, 2 vols., Detroit, Wayne State University Press.

Ruiz, Raúl, 2000, Poética del cine, Santiago de Chile, Sudamericana.

Rocha, Glauber, 1980, "Sinopse do Autor”, Tempo Glauber, disponible en: http://www.tempoglauber.com.br/glauber/Filmografia/idade.htm (consultado el 30/III/2013). 
, 1997, "An Esthetic of Hunger", en Michael Martin (ed.), New Latin American Cinema, vol. 1: Theory, Practices, and Trasncontinental Articulations, Detroit, Wayne State University Press, pp. 59-61. , 2004, "Eztetyka do Sonho", en Eduardo F. Costantini, Jr., Ana Goldman y Adrián Cangi (eds.), Glauber Rocha: Del hambre al sueño, Buenos Aires, Fundación Eduardo F. Costantini /MALBA, pp. 47-49.

Sanjinés, Jorge, 1988a, "Antecedentes históricos del cine social en Bolivia", en Hojas de cine: Testimonios y documentos del Nuevo Cine Latinoamericano, vol. 1, México, Secretaría de Educación Pública / Fundación Mexicana de Cineastas / Universidad Autónoma Metropolitana, pp. 103-106.

, 1988b, "Problemas de la forma y del contenido en el cine revolucionario", en Hojas de cine: Testimonios y documentos del Nuevo Cine Latinoamericano, vol. 1, México, Secretaría de Educación Pública / Fundación Mexicana de Cineastas / Universidad Autónoma Metropolitana, pp. 107-116.

, 1989, "El plano de secuencia integral", Cine cubano, vol. 125, La Habana, pp. 65-71.

Sarduy, Severo, 1974, Barroco, Buenos Aires, Sudamericana.

Schroeder Rodríguez, Paul A., 2011, "La fase neobarroca del Nuevo Cine Latinoamericano", Revista de Critica Literaria Latinoamericana, vol. 37, núm. 73, Lima / Boston, pp. 15-36.

, [en prensa], "La primera vanguardia del cine latinoamericano" en Aurelio de los Reyes y David Wood (eds.), Actas del Coloquio Internacional Cine Mudo en Iberoamérica: Naciones, Narraciones, Centenarios, México, UNAM.

(Artículo recibido el 21 de junio de 2013; aceptado el 10 de septiembre de 2013). 